\title{
Acompanhamento de dois pacientes diabéticos por equipe interdisciplinar e multiprofissional
}

\author{
Geny Aparecida Cantos \\ Universidade Federal de Santa Catarina \\ geny@ccs.ufsc.br \\ Liliete Canes Souza \\ Universidade Federal de Santa Catarina \\ liliete@ccs.ufsc.br
}

\section{Resumo}

Esse estudo teve como objetivo relatar o atendimento e as atividades desenvolvidas por uma equipe multiprofissional e interdisciplinar que atua na prevenção de doenças cardiovasculares junto a dois pacientes com diabetes mellitus. As atividades oferecidas por esse projeto foram: atendimento cardiológico, acompanhamento nutricional, terapia aquática, dança terapêutica, orientações por meio de palestras educativas e almoços comunitários. Na busca conjunta de soluções para as questões enfrentadas, estabeleceu-se uma estrutura de cuidados e diálogo entre os profissionais e os participantes. Os instrumentos de avaliação desse processo incluíram exames bioquímicos e compartilhamento de experiências, bem como análise de questionários aplicados. Os resultados mostraram que, em todas as ações, o diálogo e a interação favoreceram a promoção de saúde na busca de uma melhor qualidade de vida dos pacientes. Esse tipo de tratamento trouxe uma nova perspectiva para esses pacientes diabéticos, pois favoreceu a construção de novas metas e de uma nova forma de lidar com a doença.

Palavras-chave: Doenças cardiovasculares. Diabetes mellitus. Fatores de risco coronariano. Estresse.

\section{Follow up of two diabetic patients by interdisciplinary and multiprofessional team}

\begin{abstract}
This study reports the follow up and treatment developed for an interdisciplinar and multiprofessional team for cardiovascular diseases prevention with two diabetic patients. The activities offered by this project were: cardiac care, nutritional counseling, aquatic therapy, dance therapy, lectures and community lunches. In the joint search for solutions to the issues it was established a structure of care and dialogue between practitioners and patients involved. This process analysis included biochemical exams, sharing experiences and questionnaires. The results showed that, in all actions, dialogue and interaction favored the promotion of health and a better life experience for the patients. This kind of treatment brought a new perspective for these diabetes patients, favoring new goals construction and a new way of dealing with the disease.
\end{abstract}

Keywords: Cardiovascular diseases. Chronic illnesses. Diabetes mellitus. Dyslipidemia. Coronary risk factors. Stress. 


\section{\begin{tabular}{l|l} 
Extensio & Relato de Experiência
\end{tabular}}

\section{INTRODUÇÃO}

A Organização Mundial de Saúde (OMS) define o diabetes mellitus (DM) como uma síndrome de etiologia múltipla, decorrente da falta de insulina e/ou incapacidade de esta exercer adequadamente suas ações. A Federação Internacional de Diabetes, no ano de 2010, verificou que cerca de 7.632 .500 brasileiros eram portadores da doença, e, segundo a OMS, a estimativa, para o ano de 2030, é que este número atinja 11.305.000 pessoas.

Pacientes com DM têm mais que o dobro de chance de desenvolver um evento coronariano do que os não diabéticos e podem ser monitorados por exames bioquímicos. Diversos estudos já demonstraram que a diminuição dos valores de colesterol total (CT) e do colesterol da lipoproteína de baixa densidade (LDL-c) está associada a uma menor incidência de eventos cardiovasculares (CERCATO et al., 2004). Estudos demonstraram que a lipoproteína de alta densidade (HDL) está predominantemente envolvida no transporte reverso do colesterol, tendo então um papel fundamental na proteção do leito vascular. Assim, a diminuição da concentração sérica desta lipoproteína é um fator de risco isolado para doenças cardiovasculares (DCV) (BHALODKAR et al., 2004). Além disso, a HDL exerce efeito anti-inflamatório e antioxidante na parede endotelial (SPOSITO et al., 2007). Há evidências de que a hipertrigliceridemia também é um fator de risco (FR) independente para doença arterial coronariana, pois contribui com um efeito aterogênico direto das VLDL (lipoproteínas de densidade muito baixa) (CAVALETT, 2008). Somado a isso, acredita-se que a hiperuricemia possa agir como um "agente inocente" entre os principais fatores de risco reconhecidos para eventos cardiovasculares. Estudos sugerem que a hiperuricemia está ligada à obesidade, hipertensão arterial sistêmica (HAS), DM, valores diminuídos de colesterol da HDL (HDL-c) e hipertrigliceridemia (CAVALETT, 2008).

O tratamento e o controle de doenças crônicas, como DM e HAS, exigem mudanças de comportamento em relação à dieta, ao uso de medicamentos e ao estilo de vida. Essas alterações podem comprometer a qualidade de vida, se não houver orientação adequada quanto ao tratamento ou ao reconhecimento da importância das complicações que decorrem dessas patologias (BATISTA et al., 2005; CANTOS et al., 2007; SPOSITO et al., 2007; SCHÜTZ et al., 2008).

Os desafios para integrações de ações para doenças crônicas, em especial o DM, trazem uma mudança na perspectiva de vida, servindo como um elemento positivo para os indivíduos buscarem práticas que possam promover um viver mais saudável ou refletindo numa nova maneira de encarar a vida. Portanto, é fundamental que se desenvolvam pesquisas nessa área para elucidar os mecanismos determinantes da adesão e as estratégias para melhorar o estado geral do paciente (DIAS, 2008).

O projeto do Núcleo Interdisciplinar de Pesquisa, Extensão e Atendimento a Dislipidemia (NIPEAD) do Hospital Universitário da Universidade Federal de Santa Catarina, o qual é composto por uma equipe multiprofissional, tem como objetivo tratar e prevenir as DCV, oferecendo meios para um estilo de vida mais saudável, através de atendimento cardiológico, nutricional, realização de atividades físicas e controle do estresse. Os profissionais do projeto têm oferecido práticas que envolvem uma dimensão dialógica, interativa e cuidadora. Tais estratégias configuraram uma nova forma de compreender e tratar pessoas com doenças crônicas, estimulando a equipe a buscar novos modelos assistenciais que fossem orientados por diferentes profissionais envolvidos com saúde e qualidade de vida (CANTOS, 2007).

Assim, várias modalidades de intervenção foram criadas para os pacientes desse núcleo. Em 2002, iniciaram-se as sessões de Biodanza $a^{\circ}$, com a finalidade de atenuar o nível de estresse dos pacientes que participavam do programa (CANTOS, 2007). O programa intitulado Vivências Lúdicas do Coração iniciou em 2004, e este tipo de atividade tem explorado o lúdico, a brincadeira e o prazer para realização de atividades físicas, as quais consistem em dançar, caminhar, jogar, assim como fazer exercícios de alongamento, localizados, aeróbicos e de relaxamento (BONETTI, 2006).

A condição de portador de uma doença crônica requer a inserção do indivíduo em programas de tratamento, reabilitação e de adaptação às novas condição e rotina de vida. Nesse contexto, o desafio da 
integralidade do projeto Vida e Saúde, criado em 2005, veio concretizar um modelo assistencial baseado no cuidado e na promoção da saúde de pessoas com doenças crônicas (SCHUTZ et al., 2009).

Sob esta ótica, neste trabalho, foram relatadas as ações prestadas a dois pacientes diabéticos que procuraram auxílio junto ao NIPEAD. Foram identificados os fatores de risco dos indivíduos em estudo, bem como foram realizadas avaliação e comparação do quadro clínico e laboratorial ao longo do tratamento medicamentoso, nutricional, com hidroterapia e Biodanza realizado pela equipe multiprofissional e interdisciplinar, considerando a adesão desses pacientes a este programa diferenciado. Alguns parâmetros bioquímicos e emocionais foram alvo da pesquisa, sendo correlacionados aos aspectos mencionados. Além disso, com o presente relato, a importância de programas diferenciados no acompanhamento de indivíduos portadores de DM com tratamentos alternativos para DCV foi considerada, discutindo os resultados obtidos pela equipe multidisciplinar e as respectivas mudanças nas vidas de dois pacientes diabéticos que aderiram ao tratamento.

\section{Material e Métodos}

O levantamento de dados desta pesquisa se deu com dois pacientes diabéticos inscritos no programa do NIPEAD, um dos pacientes ingressou no programa em 2006 e o outro em 2008, sendo que o acompanhamento de ambos foi realizado até 2010 .

Considerou-se diabético o paciente que apresentou o valor de duas dosagens de glicemia de jejum maior que $126 \mathrm{mg} / \mathrm{dL}$, sendo que os valores inferiores a este, mas que já estavam sob medicação antidiabética também foram considerados com esta enfermidade (SBD, 2007).

A apresentação do projeto aos participantes se fez por meio de encontros dialogados com toda a equipe multiprofissional e interdisciplinar. As informações foram repassadas aos pacientes de forma clara e objetiva, em conformidade com a realidade de cada um, possibilitando-lhes a reflexão sobre sua qualidade de vida e oportunizando opções para que pudessem ter um estilo de vida mais saudável.

Primeiramente os pacientes passaram pelo exame clínico realizado pelo setor de cardiologia no SASC (Serviço de Atendimento à Saúde da Comunidade Universitária), e, após a avaliação clínica personalizada, foram solicitados exames laboratoriais. $\mathrm{O}$ agendamento e a coleta dos exames foram realizados por alunos de pesquisa e extensão.

Os seguintes parâmetros laboratoriais foram registrados: glicose (GLI), hemoglobina glicosilada (HbAlc), triglicerídeos (TG), CT, HDL-c, LDL-c, ácido úrico (URCA), creatinina (CREA) e proteína C reativa ultrassensível (PCR-as). Os exames de GLI, CT, TG, HDL-c, LDL-c, URCA e CREA foram realizados em sistema automatizado para análises bioquímicas (Dade Behring Dimension RXL ${ }^{\circledR}$, Siemens). A determinação da $\mathrm{HbA1c}$ foi realizada por cromatografia líquida de alta performance automatizada para hemoglobinas (D-10 ${ }^{\mathrm{TM}}$, BIO-RAD). A determinação de PCR-as foi realizada por nefelometria em sistema automatizado (BN-2 ${ }^{\circledR}$, Siemens).

Avaliaram-se alguns indicadores da resposta de estresse por meio de vários questionários: o estado de estresse (LIPP et al., 1999), tolerância ao estresse (SIMON, 2000), vulnerabilidade ao estresse (NAHAS, 2001) e consciência do estresse (ALVES, 2000). Uma avaliação do estado físico foi realizada por um questionário proposto por BOUCHER (1996). Além desses questionários, no segundo ano de acompanhamento do primeiro paciente, foi utilizado o questionário de Cohen (1988) para avaliação do estresse, possibilitando outro enfoque na avaliação de tal primeiro.

A educação nutricional foi utilizada como importante estratégia de intervenção. Os pacientes foram acompanhados com base no Guia Alimentar para a População Brasileira (MINISTÉRIO DA SAÚDE, 2005), o qual visa, entre outros objetivos, reduzir a incidência de doenças crônicas não transmissíveis (DCNT), por meio da alimentação saudável. Nesse tipo de atendimento, a obesidade e a dislipidemia foram relacionadas aos hábitos pessoais (padrões alimentares e pouca atividade física), independente da faixa etária. Tra- 


\section{Extensio $\mid$ Relato de Experiência}

balhou-se com a conscientização do caráter crônico da obesidade e com o controle de estresse (SILVEIRA et al., 2009)

Tanto no setor de cardiologia como no de nutrição, os pacientes foram orientados a adotarem hábitos que pudessem atenuar os riscos de doenças crônicas. Foram convidados a participarem de palestras mensais, coordenadas pelos profissionais integrantes do projeto, as quais abordaram assuntos referentes às DCV, e também a participarem de almoços comunitários mensais.

A avaliação do estado nutricional foi realizada a partir de dados antropométricos, considerando a relação do IMC, e esta foi associada com o perfil lipídico, a pressão arterial, a glicemia de jejum por 8 horas e a realização de atividade física (SCHUTZ et al., 2009). Devido à diferença entre os pacientes estudados, uma dieta adequada que considerava as especificidades de cada indivíduo foi programada a partir da avaliação do estado nutricional. Esta deu ênfase aos indicadores antropométricos, à distribuição da gordura corporal e às percepções observadas por meio de perguntas que foram formuladas a cada indivíduo.

A terapia aquática (Watsu ${ }^{\circledR}$, de water shiatsu) aconteceu nos anos de 2008 a 2010, uma vez por semana, e contou com recursos específicos, como piscina preparada com medidas, profundidade e temperatura adequadas e ambiente externo com um profissional especializado na atividade. $\mathrm{O} \mathrm{Watsu}^{\circledR}$, uma técnica de massagem em água aquecida, explorou os movimentos do corpo, como um todo. Os movimentos basearam-se em rotações verticais, laterais e combinados, dando um clima de confiança, descanso e alongamento. O controle da respiração foi repetidamente enfatizado, mesmo durante os exercícios específicos para fortalecimento da musculatura. Esta prática permitiu ao indivíduo o relaxamento do corpo e da mente, aliviando muitas vezes a dor e o estresse. A partir da sustentação pela água e de um contínuo movimento rítmico dos vários fluxos, o indivíduo experimentou um relaxamento profundo, harmonizando-se com a vida (MORRIS, 1994).

A técnica do Halliwick foi utilizada para aqueles que queriam aprender a nadar. Primeiramente o indivíduo teve um tempo de adaptação na piscina aquecida a $30^{\circ} \mathrm{C}$, de forma a estabelecer um clima de confiança. Aos poucos, utilizaram-se caminhadas, corridas, brincadeiras de flutuação e mergulhos. Posteriormente foram empregados movimentos de rotação vertical (da posição deitada para a posição em pé), rotação lateral (rolar: decúbito ventral para decúbito dorsal), rotação combinada (combinação das duas anteriores em um único movimento). Utilizou-se o equilíbrio para manter a posição do corpo enquanto o indivíduo flutuava em descanso. Em seguida, o nadador em flutuação foi levado através da água pela turbulência criada pelo grupo. Para a progressão simples, o nadador realizou movimentos de remadas curtas, e, na braçada básica, os braços foram movimentados lenta e amplamente sobre a água (RUOTI, 2000; SCHUTZ R, 2009).

No projeto proposto, a Biodanza trabalhou com cinco linhas de vivências: vitalidade, sexualidade, criatividade, afetividade e transcendência. A vitalidade e a criatividade foram trabalhadas dando ênfase aos jogos, realizados como atividades lúdicas, em duplas e trios, nos quais se enfatizou o companheirismo, considerando a capacidade integrativa dos participantes na busca de soluções; a sexualidade foi relacionada com o prazer, com a capacidade de desejar buscar e desfrutar das coisas boas da vida, da intimidade e do contato corporal; a afetividade relacionou-se ao vínculo com o semelhante, que se expressou em amizades afetivas, encontros, contatos, troca mútua de olhares; e a transcendência foi relacionada com a capacidade de ir além de si mesmo, identificando-se com o meio ambiente e com o universo (TORO, 2002). Em todas as sessões, houve uma roda de averbação, na qual se pôde compartilhar as experiências vividas e as dificuldades apresentadas.

O projeto deste estudo obteve aprovação do Comitê de Ética em Pesquisa com Seres Humanos da Universidade Federal de Santa Catarina - UFSC, sob o número 299/08, de acordo com a Resolução nº 196, de 10 de outubro de 1996, e Resolução ${ }^{\circ}$ 251, de 5 de agosto de 1997. Todos os pacientes participantes assinaram o termo de consentimento livre e esclarecido para a participação do estudo. 


\section{Resultados e Discussão}

O NIPEAD vem trabalhando com prevenção de DCV, tendo como meta buscar um estilo de vida mais saudável para pacientes que já possuem dislipidemia ou algum fator de risco associado (CAVALETT, 2008). Principais indicadores bioquímicos e diversos questionários de estresse têm sido utilizados pela equipe multiprofissional para acompanhar regularmente a evolução do quadro clínico dos pacientes. Além disso, os pacientes participaram de palestras educativas para incentivar e facilitar o autocuidado, nas quais receberam os conhecimentos necessários sobre as doenças comuns entre eles, como dislipidemia, hiperglicemia, hipertensão e estresse, bem como sobre as condutas terapêuticas pertinentes, como nutrição, atividade física e medicamentos. Na prática isso implica na capacitação dos indivíduos para reconhecerem e saberem tomar a atitude certa frente a várias situações, tais como: criar hábitos que favoreçam o exercício de atividade física, parar de fumar, desenvolver práticas adequadas que melhorem o estresse negativo, ter alimentação saudável, desenvolver cuidados para prevenir a hiperglicemia e saber avaliar os resultados de seu monitoramento bioquímico.

No caso dos pacientes diabéticos, para evitar o desenvolvimento de doenças crônicas secundárias, medidas específicas foram necessárias, a fim de melhorar o prognóstico da doença. O sistema de monitoramento da GLI foi uma ferramenta importante na detecção de variações nos valores deste parâmetro e permitiu que os pacientes tivessem uma postura mais cuidadosa com os sinais e sintomas do DM, trazendo benefícios que refletiram na aderência ao tratamento.

A atenção ao paciente diabético obrigou o envolvimento coletivo dos profissionais de saúde, que utilizaram os parâmetros bioquímicos e clínicos no controle da doença. Por exemplo, a HbA1c foi o parâmetro de escolha para o controle glicêmico a longo prazo (120 dias); a PCR-as foi o marcador de inflamação utilizado, sendo os valores elevados associados com risco aumentado para DCV; os parâmetros metabólicos como CT, TG, LDL-c, e HDL-c foram úteis sobretudo na prevenção do desenvolvimento das DCV; a CREA e o URCA serviram para avaliar a função renal. Por outro lado, sabe-se que a prática regular de exercício físico, hábitos alimentares saudáveis e bem-estar emocional melhoram o perfil lipídico, bem como outros parâmetros bioquímicos. Além disso, o controle da HAS e da glicemia exerce papel-chave na redução dos fatores de risco para DCV, estando também relacionado com a função renal (CAVALETT, 2008).

No presente trabalho, dois pacientes com diabetes mellitus foram avaliados desde seu ingresso no programa até o ano de 2010. Foram considerados os resultados obtidos com o controle glicêmico, o perfil lipídico e outras variáveis bioquímicas, a atenção clínico-nutricional, bem como o estado emocional dos pacientes.

\section{Paciente 1}

Sexo masculino, 68 anos, casado, militar e aposentado. Descobriu ser diabético no ano de 2000 e, no início de 2006, ingressou no programa de prevenção da DCV oferecido pelo NIPEAD. O monitoramento terapêutico foi realizado a cada quatro meses, por meio de questionários de estresse, de exames bioquímicos, de consultas cardiológicas e nutricionais. O paciente também participou das atividades físicas de Watsu', Halliwick e Biodanza:.

O acompanhamento do estado emocional do paciente foi avaliado por questionário para o estresse validado (LIPP, 1999). Em 2006, dos doze itens do questionário, quatro foram assinalados: sentia-se ansioso, dormia pouco, tinha o hábito de pensar em um só assunto e realizava atividades com um nível de competência abaixo do normal. Esses resultados indicaram alto nível de estresse, ou seja, o paciente estava exigindo demais do seu organismo e estava chegando ao limite. Outro questionário respondido para avaliação do estresse (SIMON, 2000) indicou que o indivíduo se sentia ansioso de vez em quando e focalizava pensamentos angustiantes ocasionalmente. O resultado mostrou um nível moderado de tensão, que certamente poderia ser melhorado. Entre os sintomas de estresse apontados, somam-se problemas de memória, dificuldades sexuais, angústia e perda de senso de humor. 


\section{Extensio $\mid$ Relato de Experiência}

Para investigar a vulnerabilidade ao estresse, foi aplicado um questionário elaborado por NAHAS (2001). Os resultados deste, em 2006, mostraram que o paciente ficava sempre muito ansioso quando seus planos não saíam do modo que planejava, sempre odiava ser interrompido quando estava ocupado com alguma tarefa e ficava sempre incomodado quando seus planos dependiam de outras pessoas. Geralmente se sentia desconfortável quando tinha que esperar em longas filas e ficava nervoso quando dirigia ou estava atrás de alguém que dirigia muito devagar. As discussões também o deixavam alterado. Assim, ficou claro que o paciente, em muitas situações, poderia agir de forma mais tranquila.

A avaliação do estado físico foi realizada com o questionário de Boucher (1996). Os resultados obtidos demonstraram que o paciente tinha o sono irregular, não praticava esporte nem realizava atividades físicas semanalmente. Seus hábitos alimentares não eram bem equilibrados, pois fazia muito uso de refrigerantes e sobremesas, tendo peso corpóreo muito acima do ideal.

Os exames laboratoriais, realizados em 2006 (Tabela 1), revelaram valores de GLI, HbA1c, CT, TG e URCA dentro da faixa dos valores de referência. O LDL-c estava próximo ao intervalo considerado ótimo, porém com valor pouco acima do limite superior deste. O valor de CREA estava acima da faixa de referência, indicando, possivelmente, o comprometimento renal comum em pacientes diabéticos. Através dos exames cardiológicos, foi constatada pressão arterial elevada.

Nesse período de iniciação ao programa (2006), o paciente fazia o uso de medicamentos para tratamento da dislipidemia, DCV, DM e HAS.

Em 2008, após dois anos de adesão ao programa do NIPEAD, os questionários anteriormente citados foram refeitos pelo paciente. No questionário proposto por LIPP (1999) para avaliar o estresse, o paciente assinalou somente um dos doze campos, alegando que continuava com o distúrbio do sono. A melhora resultou em um nível de estresse moderado, indicando que a vida ainda estava um pouco estressante. Nesse sentido, o paciente foi aconselhado a perceber se o que estaria exigindo demais dele seria o mundo em volta ou ele próprio. Houve melhora também no questionário sobre avaliação do estresse (SIMON, 2000), no qual o paciente alegou que se sentiu ansioso somente de vez em quando e que teve insônia. Entretanto, quanto ao questionário de avaliação da vulnerabilidade (NAHAS, 2001) e ao questionário de avaliação do estado físico (BOUCHER, 1996), os resultados permaneceram praticamente inalterados. Também foi aplicado outro questionário para escala de estresse (COHEN, 1988). O resultado foi exatamente o limite entre conviver com níveis toleráveis de estresse e conviver com níveis elevados de estresse, indicando que o paciente ainda não sabia lidar com dificuldades e problemas e que ele poderia se tornar suscetível à convivência com nível elevado de estresse, prejudicando seu desempenho.

Quanto aos exames bioquímicos, em 2008 (Tabela 2), os valores de CT diminuíram; porém, os de TG aumentaram. Os TG elevados podem se tornar precursores do colesterol, agravando ainda mais a situação do paciente, já predisposto a alto risco para DCV (JUNQUEIRA, et al., 2011). Assim, foi indicada uma dieta com ingestão calórica reduzida. Houve aumento no valor do HDL-c e redução no valor do LDL-c, ambos ficando dentro dos valores de referência, sendo este resultado atribuído à prática de exercício. Houve redução nos valores de Hb1Ac e URCA, que permaneceram dentro da faixa de valores de referência. Somente o valor de CREA permaneceu acima do recomendado. Sua concentração, entretanto, diminuiu quando comparada ao exame de 2006 (Tabela 2).

No ano de 2008, o paciente ainda fazia uso de medicamentos para dislipidemia, DCV, DM e HAS e também passou a fazer uso de antidepressivos e anti-hiperuricêmicos.

Em 2010, após quatro anos de adesão ao programa, o paciente apresentou os seguintes resultados: no questionário do estado de estresse (LIPP et al., 1999), o paciente assinalou que tinha distúrbios do sono pelo menos quatro vezes na semana, mas o resultado final obtido indicou bem-estar positivo do paciente. Ao avaliar o questionário proposto por Simon (2000), pode-se perceber que o paciente estava se sentindo muito bem, sem sentimentos negativos que pudessem interferir na sua vida.

Quanto aos exames bioquímicos (Tabela 1), a GLI permaneceu controlada e dentro dos valores de referência. Se comparado a 2008, o valor de CT aumentou; porém, ainda estava dentro da faixa de referência 
e bem abaixo do valor obtido no início do programa (2006). Houve diminuição no valor de TG, bem como no valor de LDL-c, indicando melhora do quadro clínico, considerando que estes são fatores de risco para DCV. Os valores de URCA, HB1Ac e PCR-as continuaram dentro das faixas de referência. No entanto, a concentração de CREA, que já se encontrava acima do valor esperado, aumentou. Esse aumento pode ser preocupante, pois está correlacionado com o comprometimento da função renal (MAGRO, et.al., 2007).

A melhora do nível de estresse desse paciente foi acompanhada por uma alternância de valores nos exames bioquímicos, indicando certa evolução positiva na maioria dos parâmetros laboratoriais avaliados no ano de 2008 e uma ligeira piora, se comparado aos últimos exames (2010). Contudo, percebeu-se que o tratamento multiprofissional e interdisciplinar diferenciado proposto pelo NIPEAD proporcionou a este paciente melhora na sua qualidade de vida, instruindo-o em vários aspectos e propondo novas formas de lidar com a doença.

TABELA 1: Perfil bioquímico do paciente 1.

\begin{tabular}{c|c|c|c|c}
\hline \multicolumn{1}{c}{ Exame } & $\mathbf{2 0 0 6}$ & $\mathbf{2 0 0 8}$ & $\mathbf{2 0 1 0}$ & Valor de referência \\
\hline GLI & 86 & 95 & 95 & $60-100$ \\
\hline CT & 182 & 151 & 165 & $<200$ \\
\hline TG & 121 & 170 & 156 & $<150$ \\
\hline HDL-c & 51 & 59 & 52 & $\begin{array}{c}\text { Baixo: } \leq 40 \\
\text { Alto: } \geq 60\end{array}$ \\
\hline LDL-c & 107 & 93 & 82 & $<100$ \\
\hline HbA1C & 5,70 & 5,20 & 5,60 & 4,3 a 6,1 \\
\hline URCA & 7,9 & 6 & 7,4 & 3,5 a 7,2 (homens) \\
\hline CREA & 1,5 & 1,3 & 1,5 & 0.5 (mulheres) \\
\hline PCR-as & 0,36 & 0,55 & 0,309 & $<5$ \\
\hline
\end{tabular}

$G \overline{L I}=$ glicose, $C T=$ colesterol total, $T G=$ triglicerídeos, $H D L-c=$ colesterol da lipoproteína de alta densidade, $L D L-c=$ colesterol da lipoproteina de baixa densidade, HbAlc = hemoglobina glicosilada, URCA = ácido úrico,

$C R E A=$ creatinina, $P C R$-as $=$ proteína $C$ reativa ultrassensivel. Valores em $\mathrm{mg} / \mathrm{dL}$ para todos.

\section{Paciente 2}

Sexo feminino, 55 anos, casada, mãe de uma filha e dona de casa. Aderiu ao programa oferecido pelo NIPEAD em 2008. No exame cardiológico, foi realizada uma avaliação clínica personalizada. Foram solicitados exames com o objetivo de avaliar o perfil lipídico, o risco cardiovascular e verificar suspeitas de outras doenças, por isso outros exames mais complexos foram solicitados. Pela avaliação cardiológica e pelo resultado dos exames bioquímicos, a paciente em estudo foi classificada no grupo de alto risco para DCV e com HAS.

No setor de nutrição, a paciente foi submetida a exame antropométrico (massa corporal em kg, estatura em $\mathrm{m}$, perímetro da cintura e quadril em $\mathrm{cm}$ ). O IMC (índice de massa corporal), obtido pela divisão da massa corporal, em quilogramas, pelo quadrado da estatura, em metros $\left(\mathrm{IMC}=\right.$ massa $\left.(\mathrm{kg}) / \mathrm{estatura}^{2}\right)$, foi 35,1, sendo constatada obesidade tipo II (SILVEIRA et al., 2009). Pelos relatos da própria paciente em consulta nutricional, sabe-se que, mesmo estando ciente da gravidade da doença, havia ingestão de doces e refrigerantes. Nesses casos, a importância da educação nutricional auxiliou na estratégia de intervenção frente às DCV.

Pelos exames bioquímicos, pode-se notar que o URCA estava elevado $(8,2 \mathrm{mg} / \mathrm{dl})$, devido à paciente ser portadora de artrite reumatoide. De fato, a literatura mostra que valores de URCA superiores a $8 \mathrm{mg} /$ dL no plasma sanguíneo indicam que pode haver deposição do mesmo em qualquer tecido do organismo, 
dependendo muito das condições locais, possibilitando o surgimento de processo inflamatório como gota, artrite e nefrite (JUNQUEIRA, et al., 2011).

Outros parâmetros analisados foram o HDL-c, que apresentou valor abaixo da referência, e os TG, que estavam elevados (Tabela 2). O HDL-c baixo pode estar relacionado ao IMC maior ou igual a 30. Estudos mostram que a obesidade está relacionada também a outras alterações, tais como os valores elevados de TG e a maior prevalência de HAS. Por outro lado, programas de exercícios físicos, com atividades aeróbias e de resistência muscular localizada, resultaram na redução da glicemia de jejum, da HbAlc, dos TG e do IMC, bem como no aumento do HDL-c e na melhora da eficiência cardíaca, mostrando a importância da atividade física bem orientada (BATISTA et al., 2005). Quanto às medidas do controle glicêmico, a redução nos valores de HbAlc é um indicador de controle do DM e está correlacionada com a redução do aparecimento e/ou da progressão de complicações crônicas (JUNQUEIRA, et al., 2011).

O valor de HbA1c encontrado estava acima da referência (Tabela 2), o que correlacionava com o perfil da paciente, que consumia produtos com altas concentrações de GLI durante períodos longos de tempo, não realizava exercícios físicos e não tinha, portanto, controle sobre a doença. Outros fatores, como seu estado emocional, também poderiam alterar eventualmente a concentração de GLI sanguínea por curtos períodos (VOLP, 2006).

Uma forma de averiguar seu estado emocional foi por meio de dois questionários de estresse: consciência (ALVES, 2000) e estado de estresse (LIPP et al., 1999). No primeiro questionário pôde-se observar que sua vida conjugal era causa da contrariedade, agressão ou frustração. Às vezes ela sentia falta de afeto, visto que sua vida sexual era pouco satisfatória. Declarou que tinha dificuldades em se defender sem se irritar e que estava se sentindo cansada, com pouca energia e entusiasmo. É importante frisar que a paciente às vezes perdia a paciência facilmente e tinha tendência de ver mais o aspecto negativo do que positivo das coisas. As respostas deste questionário indicaram que ela estava frequentemente estressada, sendo que os fatores mais importantes foram seu temperamento, personalidade, vida conjugal e comportamento. Esses dados mostraram que a paciente em questão necessitava de uma mudança não só nos fatores externos que influenciavam na sua vida, mas também nas suas próprias atitudes e pensamentos. No segundo questionário, pôde-se notar que a paciente estava muitas vezes desanimada, nervosa e que não tinha controle sobre seu comportamento, pensamentos, emoções ou sentimentos. Na maioria das vezes, se incomodava por alguma outra doença ou desordem orgânica e sentia muitas dores. Ela tinha muitos temores sobre sua saúde e já fazia algum tempo que vinha se sentindo cansada e esgotada. Baseando-se na contagem dos pontos obtidos, seu estado indicou sofrimento ao estresse.

Como forma de diminuir os sintomas do estresse psicológico e melhorar seu estado geral de saúde, a paciente foi indicada para usufruir do programa aquático de Watsu e da técnica de Halliwick, associados com a Biodanza . Assim, durante dois anos, ela participou com assiduidade destas terapias, criando vínculos afetivos com os demais participantes. Apesar de todas suas dores e consequente limitação física, a paciente considerou a terapia aquática fundamental para sua recuperação física e emocional. Em depoimento, ela disse que a água era capaz de dissolver tensões, revitalizar, melhorar sua respiração. Disse também que na água ela se movimentava melhor, com mais segurança e alegria, voltando para casa com mais energia e disposição, e tendo um sono noturno mais tranquilo.

Em 2010, os exames bioquímicos constataram um aumento na GLI, que deveria estar controlada devido aos medicamentos. O percentual de HbA1c também aumentou, fato preocupante especialmente por ter ocorrido em conjunto com o aumento de GLI. O valor de CREA estava dentro do esperado, indicando uma relativa melhora em relação aos exames de 2008. O valor de URCA, embora tenha diminuído, continuava acima da referência. O valor de PCR-as estava levemente elevado em comparação ao resultado anterior, e ambos estavam acima do valor de referência, fato possivelmente decorrente de a paciente ser diabética e hipertensa, pois estas condições estão diretamente associadas ao alto risco para DCV (LIMA et al., 2007).

O valor de HDL-c aumentou pouco e permaneceu abaixo do valor de referência, fato atribuído à falta de exercício físico. A paciente alegou não praticar exercício físico (somente a terapia aquática oferecida pelo programa, uma vez por semana), pois sentia muita dor nos joelhos e costas, impedindo-a de se exercitar o quanto gostaria. $\mathrm{O}$ valor de LDL-c diminuiu, ficando próximo ao intervalo considerado ótimo. Ao comparar as tabelas nutricionais da paciente (2008-2010), pode-se notar que a principal alteração foi em relação à ingestão de açúcar. Doces e refrig- 
erante deixaram de fazer parte dos hábitos alimentares da paciente, que também diminuiu a quantidade de óleo e frituras. Essa conduta pode ser correlacionada aos valores de TG, que ficaram dentro da faixa de referência.

Os questionários de estresse respondidos (estado de estresse e consciência do estresse) mostraram que não houve mudança comportamental. Seu modo de ser, pensar e agir em relação à família, ocupação e sociedade continuou influenciando a paciente no seu estado de estresse. As dores ocasionadas, sobretudo pela artrite reumatoide, a impediam de realizar exercícios físicos e atividades domésticas. Portanto, seu único conforto era participar das atividades de Watsu e Halliwick, nas quais encontrava amigos e sentia-se acolhida, podendo realizar algum exercício sem tanto esforço físico e relaxar. Notou-se, pois, que, apesar das dificuldades apresentadas em relação ao comportamento desta paciente, seus exames bioquímicos melhoraram provavelmente devido à sua participação assídua nas práticas de Watsu', Halliwick e Biodanza e também às mudanças quanto aos hábitos alimentares.

TABELA 2: Perfil bioquímico do paciente 2

\begin{tabular}{|c|c|c|c|}
\hline Exame & 2008 & 2010 & Valor de referência \\
\hline GLI & 149 & 243 & $60-100$ \\
\hline CT & 185 & 190 & $<200$ \\
\hline TG & 249 & 139 & $<150$ \\
\hline HDL-c & 31 & 32 & $\begin{array}{c}\text { Baixo: } \leq 40 \\
\text { Alto: } \geq 60\end{array}$ \\
\hline LDL-c & 118 & 110 & $<100$ \\
\hline HbA1C & 7,2 & 7,8 & 4,3 a 6,1 \\
\hline URCA & 7,6 & 6,8 & $\begin{array}{l}3,5 \text { a } 7,2 \text { (homens) } \\
2,6 \text { a } 6,0 \text { (mulheres) }\end{array}$ \\
\hline CREA & 8,7 & 0,7 & $0,5-1,2$ \\
\hline PCR-as & 5,41 & 5,5 & $<5$ \\
\hline
\end{tabular}

$G L I=$ glicose, $C T=$ colesterol total, $T G=$ triglicerídeos, $H D L-c=$ colesterol da lipoproteína de alta densidade, $L D L-c=$ colesterol da lipoproteina de baixa densidade, HbA1C = hemoglobina glicosilada, Urca = ácido úrico, Crea = creatinina, PCR-as = proteína C reativa ultrassensivel. Valores em $\mathrm{mg} / \mathrm{dL}$ para todos os analitos, com exceção da HbAlc, cujos valores são em \%, e da PCR-as, com valores em $\mathrm{mg} / \mathrm{L}$.

Trabalhos realizados pelo NIPEAD têm evidenciado a importância da orientação nutricional como medida de prevenção para DCV. Dentro dessa perspectiva, a equipe tem realizado o acompanhamento nutricional de pacientes que participam do projeto e tem observado mudanças positivas no seu estilo de vida (CANTOS et al., 2008; SCHÜTZ et al., 2009).

O sedentarismo também pode ser considerado como um fator de risco independente para DCV, já que a realização de exercícios físicos regulares está associada com a redução da incidência da doença (CAVALETT, 2008). A prática de exercícios físicos faz parte dos procedimentos adotados pelo NIPEAD como medida profilática e terapêutica para todos os pacientes com fator de risco para DCV. Este combate à dislipidemia por meio de exercícios físicos foi recomendado pela literatura como parte integrante de seu tratamento (SPOSITO et al., 2007).

Com o exposto, verificou-se a necessidade de mudança no estilo de vida dos pacientes, adotando dieta adequada, prática regular de exercícios físicos e conscientização da importância desses cuidados para a saúde e para o controle da doença. Nesse sentido, os dados do presente estudo ratificam a importância de um melhor controle metabólico para evitar as complicações decorrentes do DM. 


\section{Extensio $\mid$ Relato de Experiência}

\section{Considerações Finais}

É fundamental que pessoas com fator de risco para DCV busquem melhorar a qualidade de vida por meio de terapias alternativas usufruídas concomitantemente com a terapia farmacológica. Os indicadores de resultados clínicos e bioquímicos foram ferramentas importantes no acompanhamento do indivíduo a partir de metas individuais, previamente estabelecidas e discutidas entre a equipe e o paciente. Assim, por meio da análise dos questionários sobre estresse, notaram-se melhoras no estado emocional dos pacientes, fato que pode ser atribuído à mudança no estilo de vida, no hábito alimentar e no incentivo à prática de exercício físico, bem como ao abandono de hábitos prejudiciais, como o tabagismo, o sedentarismo, entre outros. No que concerne aos fatores mais valorizados, constataram-se a interação dos pacientes com o grupo, a interação destes com a equipe multiprofissional de saúde e o acolhimento da equipe.

Os resultados quantitativos e qualitativos obtidos mostraram o quanto a equipe interdisciplinar e multiprofissional do NIPEAD interveio positivamente na vida dos pacientes avaliados neste artigo. Contudo, há necessidade de as instituições formadoras em saúde investirem na capacitação de profissionais para trabalharem com grupos, discutindo os fatores que favorecem positivamente no processo de ensino-aprendizagem em diabetes. Esse processo dever ser integrado às intervenções clínicas e envolver todos os membros da equipe de forma multiprofissional e interdisciplinar, incluindo a participação ativa do paciente em seu tratamento.

\section{Referências}

BATISTA, M. C. R., et al. Avaliação dos resultados da atenção multiprofissional sobre o controle glicêmico, perfil lipídico e estado nutricional de diabéticos atendidos em nível primário. Revista de Nutrição, v. 18, n. 2, 2005.

BONETTI A. Vivências lúdicas do coração. Florianópolis, 2006. Tese (Doutorado em Educação Física) Universidade Federal de Santa Catarina.

BOUCHER, F; BINETTE, A. Vença o Estresse. São Paulo: Editora Loyola, 1996.

CANTOS, G. A.; SCHUTZ, R. O efeito terapêutico da biodança sobre o estresse psicológico. Revista Pensamento Biocêntrico, v. 7, n. 4, p.21-25, 2007.

CANTOS, G. A.; SCHÜTZ, R.; ROCHA, M. E. Associação das técnicas de Watsu e Halliwick com a Biodanza aquática, como forma de melhorar o estresse psicológico de pacientes com doenças crônicas. Revista Pensamento Biocêntrico, v. 9, n. 4, p.69-83, 2008.

CANTOS, G. A., et al. Atendimento multiprofissional e interdisciplinar para pacientes com dislipidemia de uma comunidade universitária: relatos de uma experiência de 10 anos. Revista Ciências da Saúde, v. 26, p. 33-42, 2007.

CAVALETT, C. Avaliação do quadro clínico e laboratorial de pacientes com alto risco para doença arterial coronariana atendidos por um programa multiprofissional e interdisciplinar. Florianópolis, 2008. Dissertação (Mestrado em Farmácia) - Universidade Federal de Santa Catarina.

DIAS, M. S. A.; VIEIRA, N. F. C. A comunicação como instrumento de promoção de saúde na clínica dialítica. Revista Brasileira de Enfermagem, v. 61, n. 1, p. 71-77, 2008. 
JUNQUEIRA, C.L, COSTA G.M., MAGALHÃES M.C.M. Síndrome Metabólica:o risco cardiovascular é maior que o risco dos seus componentes isoladamente? Revista Brasileira de Cardiologia, v. 24, n.5, p:308-315, 2011

LIPP, M. E. N. O que eu tenho é estresse? De onde ele vem? São Paulo: Editora Contexto, 1999.

LIMA, L. M., et al. High-sensitivity C-reactive protein in subjects with type 2 diabetes mellitus and/or high blood pressure. Arquivos Brasileiros de Endocrinologia e Metabologia, v. 51, n. 6, p. 956-960, 2007

MAGRO, M. C. S. et al. Avaliação da função renal: creatinina e outros biomarcadores. Revista Brasileira de Terapia Intensiva, v. 19, n. 2, p. 182-185, 2007

MINISTÉRIO DA SAÚDE. Secretaria de Atenção à Saúde, Coordenação-Geral da Política de Alimentação e Nutrição, Guia alimentar, para a população brasileira Promovendo a Alimentação Saudável, Série A. Normas e Manuais Técnicos Brasília - DF, 2005.

MORRIS, D. M. Aquatic rehabilitation for the treatment of neurological disorders. Journal of Back and Musculoeskeletal Rehabilitation, v.4, p.297-308, 1994.

NAHAS, M.V. Atividade física, saúde e qualidade de vida. Conceitos e sugestões para um estilo de vida ativo. Londrina: Editora Midiograf, 2001.

RUOTI, R. Reabilitação Aquática. São Paulo: Manole, 2000.

SCHÜTZ, R.; GAZZOLA, J.; BALEN, M. G. Orientação nutricional na prevenção e controle de doenças cardiovasculares numa comunidade universitária. Revista Extensio. v. 6, n.7, p.126-132, 2009.

SCHÜTZ, R., et al. Associações entre diferentes fatores de risco para doenças cardiovasculares e hipertensão arterial de pacientes com dislipidemia pertencentes a uma comunidade universitária. Revista Brasileira de Análises Clínicas. v. 40, n. 2, p.97-99, 2008.

SCHUTZ, R.; ROCHA, M. E.; BALEN, M. G.; HERMES, E. M.; SILVA, C. M.; CANTOS, G. A. O método watsu e halliwick associados com a biodança: dados preliminares de uma população com doenças crônicas. Revista Pensamento Biocêntrico, v. 10, p. 3-15, 2009.

SILVEIRA, M., et al. Fatores de risco para doenças cardiovasculares e suas associações com obesidade. Revista Ciências da Saúde. Florianópolis, v. 28, n.1, p.23-30, 2009.

SIMON, R. M. M. Estresse esclarecendo suas dúvidas. São Paulo: Editora Ahora, 2000.

SPOSITO, A. C., et al. IV Diretriz Brasileira sobre Dislipidemias e Prevenção da Aterosclerose: Departamento de Aterosclerose da Sociedade Brasileira de Cardiologia. Arquivo Brasileiro de Cardiologia, v. 88, n. 1, p. 1-19, 2007.

TORO, R.A. Teoria da Biodança. Coletânea de textos, ALAB. Fortaleza: Olavobrás/ EPB, 2002.

VOLP, A. C. P.; ALFENAS, G. C. G. Glycemic index, glycemic load and cardiovascular diseases. Revista Brasileira de Nutrição Clínica, v. 21, n. 4, p. 302-308, 2006. 